\title{
Strained agricultural farming under the stress of youths' career selection tendencies: a case study from Hokkaido (Japan)
}

\author{
Muhammad Usman (1) 1,4凶, Akinori Sawaya ${ }^{2}$, Mari Igarashi ${ }^{1}$, Jeffry Joseph Gayman ${ }^{3}$ \& Rakesh Dixit ${ }^{2}$
}

\begin{abstract}
Although job availability in Japan is at its highest in 24 years, the unemployment rate has remained unchanged. On one hand, certain fields are saturated with employees while on the other hand, the rural areas of Hokkaido are in desperate need of agricultural workers. At the same time, the aging population in Japan is an emerging challenge. The flat unemployment rate in conjunction with the rapidly aging farmers' population can possibly reduce the food self-sufficiency rate, raise Japan's dependency for international food products and increase import expenses. Thus, these factors can tip the socio-economic balance of the struggling economy. For the present research, different surveys were conducted not only in various farming corporations of Hokkaido but also 20 farmers were directly contacted and interviewed. In addition, adolescents' (aged 16-18 years) career choices were studied through questionnaires administered to 157 students at Hokkaido's Sapporo Kaisei Secondary School. It was found that, in rural areas of Hokkaido, relocation of youth to the cities is probably the main cause of the shortage of workers. In Sapporo city, among adolescents who had already chosen a career path, around $76 \%$ wanted to enter the science and technology field. This trend can result in intense competition and "saturation" in science and technology fields and many vacant slots in the others related to agricultural farming. This behavior is probably maintaining the unemployment rate, regardless of the number of job vacancies. In addition, according to our survey, considering career paths, parents and teachers provide general guidance that has very little influence on adolescents' career decisions. So, a more detailed career counseling is suggested.
\end{abstract}

\footnotetext{
${ }^{1}$ Department of Workforce and Population Research, Hokkaido Agriculture Facilitators, Sapporo, Japan. ${ }^{2}$ Sapporo Kaisei Secondary School, Higashi 21-1-1, Kita 22, Higashi-ku, Sapporo, Hokkaido, Japan. ${ }^{3}$ Graduate School of Education, Hokkaido University, Sapporo, Japan. ${ }^{4}$ Present address: King Abdullah University of Science and Technology (KAUST), Thuwal, Saudi Arabia. ${ }^{凶}$ email: usman.lal@frontier.hokudai.ac.jp
} 


\section{Introduction}

verall the world's working-age population (between 15 to 64) shows a rising trend (Eberstadt, 2010). However, this increase will mainly be concentrated in the less developed areas of the world (Cohen, 2006). In the more developed regions of the world, the working-age population is projected to decline (Bermingham, 2001). Japan is among the nations with the highest percentage of the population aged 65 or older. In Japan, around 2000 , there were 4 working-age individuals per one elderly person, however, by 2050 this ratio will be 1.7 to 1 (where 1.7 represents the average of working individual and 1 represents the person over 65 years of age) (Bermingham, 2001). Considering family support, Japan has a long tradition of the "combined family system" in which support flows from married children to older parents. However, now with the increasing trend of singles living with their parents in many cases support is flowing from the older to the younger (Nishi and Kan, 2006). In recent times, not only is there a rapid increase in the aged population, but the total size of the population has started to decrease. This kind of demographic imbalance has started to show its impacts on the country's economy.

Japan's social security system mainly includes pension schemes and medical plans. Now there is a rapid increase in these expenses with the passage of time. Since their launch, Japan's pension schemes were established on the principle of "reserve financing". Just in 37 years, from 1965 to 2002, the reserve fund amount for all the public pension schemes grew from zero to roughly onethird of the GDP. Despite this capital accumulation, the current rapid aging population coupled with the combination of changes in the social security system has required the government to move away from reserve financing to pay-as-you-go financing using tax revenues. With the passage of time, in the public pension schemes, there is an increasing transfer component, which questions the intergenerational equity, prompting further policy changes so that Japan's system is fair to the young workers (IPSS, 2014). The amount allocated to the medical care plans has risen continuously and these days the costs have escalated because of the unusually high rate of hospitalization.

The aging population ultimately affects labor market institutions and policies. There are numerous ways to help offset rising pension and health system costs: (i) Equality of employment opportunities coupled with improved working conditions so that older workers can help to alleviate the negative effects of the declining labor workforce. (ii) An extension of the retirement age. (iii) An enhanced role of women in the labor force. (iv) Immigration can also have an effect on population age structures; however, it seems highly unlikely that it can fully compensate for a declining labor force.

For points (i)-(iii), one also needs to consider the "type of job". As compared to normal office work, agriculture and construction industry jobs are more physically challenging and may need more input from young male workers.

As for point (iv), international migration's effect on population age structures is usually small, though not always negligible (United Nations, 2001). Usually, the migrants add to the younger population as they are in their young adult age and have children. However, a sustained influx of migrants is required in order to have a long-term effect on the age structure of a population. In countries with below-replacement fertility (such as Japan), in order to offset the reduction of population numbers, a much higher level of immigration will be required compared to the currently managed influx (United Nations, 2001). This argument would also hold for Europe, where the gap between dependents (over 64 years) and the working (15-64 years) is widening with the passage of time (COEC, 2007). On the other hand, the huge influx of immigrants required to maintain the constant ratio between those aged over 65 and the working-age population would not be sustainable. The population growth would mainly be governed by the new immigrants and their descendants and this scenario underestimates the fact that the ongoing population ageing process has its own inbuilt powerful momentum, so that a rapid population increase to compensate the aging population would have unsustainable consequences (Coleman, 2006). Also, permanent immigration may result in political, economic and social tension in the host country (Yamanaka, 1993).

For Japan, the aging population is an emerging social challenge (Yashiro, 1997; Suzuki, 2006). For a sustainable society, the balance between the working-age (15-65) and the dependent population (aged $1-15$ and $>65$ ) is always important to maintain (Kaneko et al., 2008). The increase in the dependent population may tip the socio-economic balance, creating additional problems for a struggling economy (Villanueva, 2000). Japan has amended its labor laws, and is now allowing foreign workers into the country; however, there remains an uncertainty as to whether it will be possible to sustain the flow of workers as expected. Japan has a very different culture and language from the rest of the world and mostly there remains a gap between the freshly hired foreign employees and the local company employees. It has been observed that this gap usually widens with the passage of time and mostly results in job termination. So, it is important that along with flexible immigration policies, countries should attempt to wield their indigenous working-age population in the most effective way. This can become possible by understanding the current career selection trends of youth and trying to find solutions accordingly.

In conjunction with aging, an emerging challenge for Japan is that there is a huge competition in certain jobs (related to the applied sciences), while others (related to natural sciences and social science) are in heavy need of a workforce (Usman and Tomimoto, 2013). It has been recently observed that regardless of the number of jobs, the nationwide unemployment rate remains flat (JT, 2016) and recent data shows a slight increase in the unemployment rate (JT, 2018). This aspect, the link between saturation and competition in a certain field to the current overall flat unemployment rate needs further investigation and it has been explored in this research. For the current research, we have selected farming as a test career profession and Hokkaido as our study area.

In Japan, $>60 \%$ of the farmer population is aged above 65 . The rapidly aging farming society in Japan would not only decrease Japan's food self-sufficiency percentage but also result in a low domestic farming business and consequently reduced collection of revenues. Also, this not only has potential to raise Japan's international dependency for food but will result in increased import expenses. Although, with the decreasing number of farmers, the number of farming corporations is increasing (Hosoyama, 2011) and it seems an alternative to the aging farmer population. Most of the farming companies are located close to the cities, as there is a higher chance to find workers and ease to reach the main market. However, the reality on the ground is that even staying in the vicinity of urban areas, the farming corporations are having a hard time securing young employees. Also, another reality is that farmers do not feel comfortable handing over their lands to farming corporations as there is a general perception that farming corporations are business entities that prioritize high profit at the expense of land conditions and fertility. Francks et al. (1999) reported that in Japan, farm households are not able to reproduce themselves and the lands lie abandoned. However, recently, not only just in the remote farming areas, but also close to the cities, the problem of aging has become so serious that the abandoning of not only farmlands but now even houses is quite prominent. 
Compared to Japan's food self-sufficiency hovers at only $38 \%$ (Kinezuka and De Wit, 2020), Hokkaido is an agricultural province with a food self-sufficiency rate of $200 \%$ (DAHG, 2017). We have selected Hokkaido for the present research because the management area per farm household is about 14 times as large as that of other prefectures and Hokkaido is considered the "food basket" of Japan. Farming is one of the major contributors to the prefecture's economy. However, Hokkaido follows the nationwide decline in the number of young farmers. The breakdown by age of farmers indicates that those aged 65 or older account for $65 \%$ of the total but those aged 40 or younger account for only $10 \%$, showing a remarkable imbalance (MAFFJ, 2017). The farmers' corporations we surveyed confirm that farmers are in desperate need of workers. Meanwhile in Sapporo (the major city of Hokkaido), there is much competition for jobs related to science and technology or those jobs that will provide chances to remain in the city.

For Hokkaido, there are government research institutions that provide statistical data (DAHG, 2017; Ministry of Agriculture, Forestry and Fisheries, 2018) and some previous literatures provide an insight into the prefecture's farming (Nihei, 1991; Hosoyama, 2011; Hosoyama, 2013; Koshiyama, 2019; Shin and Kim, 2019). However, no study to date had combined data on farming with youth career choice tendencies. Career choice can result in psychological, physical and socio-economic inequalities that persist well beyond youth into an individual's adult life (Robertson, 2014; Bubic and Ivaniševi, 2016). So, it is important to understand youth career choices alongside the current challenges in farmers' lives. The purpose of the current research is to explore the impacts of relocation and the career selection tendencies and perception of young people living in the city about agriculture, the major source of income for their prefecture. This can help to design policies to motivate youth about the opportunities available in farming and rural life and can be a contributing factor to balancing the unemployment rate and advancing the sustainable society of Japan.

This article is based on our novel research, which is the first to directly approach the youth in high school and full-time farmers in the villages of Hokkaido to draw conclusions by directly interacting with both of these sectors of society. Surveys were conducted to various farming corporations in Hokkaido as well as to 20 farmers, who were directly contacted and interviewed. Meanwhile, youth of Sapporo Kaisei Secondary School were approached through questionnaires.

Our research data indicates that the adolescents in Sapporo have no intent to adopt farming as a career path. Our research suggests that the misinformation related to the farming profession combined with fascination of youth with the science and technology-related jobs (nearly all such jobs are available in the cities) are the main factors that cause youth to move away from the farming profession. Additionally, a demand for farmingrelated vocational institutes is nearly non-existent.

Here, we review and discuss demographic variables, farming, the educational system, the social perception of vocational institutes, and the current career guidance system in Japan and finally suggest some possible solutions to raise the students' interest in agriculture farming and in related vocational training institutes.

\section{Literature review}

A review of demographic variables in Japan. The aging population has become an important social and economic issue in Japan. The population of Japan is 126.71 million as of October 2017. The people above the age of 65 are 35.15 million, which constitutes around $27 \%$ of the total population and it is predicted that the population will fall below 100 million by 2053 . According to UN data, the ratio of young (aged 15-24) accounts for only $12.3 \%$ of the total population in Japan. In comparison, it is $26 \%$ across the world (Yokoyama and Birchley, 2020). According to government statistics, in Japan, the life expectancy at birth for females is higher than males; i.e., 87.14 for females and 80.94 for males and is predicted to increase by 2065 by which time females will have a 91.35 year life expectancy and males 84.95 years (Cabinet Office, 2018). It is quite alarming that the yearly birth rate in Japan has fallen continuously since 1975. While the longevity of the women is increasing their fertility rate is decreasing, with the average age of women giving birth to their first child being 30.7 years old. The cited reasons are that childbirth includes the financial burden of raising and educating children, problems conceiving (Usman and Tomimoto, 2013) and wishing to pursue a career and getting married at a later age. Presently (2017), the percentage of the 65-69-year-old labor force to the overall population is $45.3 \%$, and this has increased year-onyear since 2004 (Yokoyama and Birchley, 2020).

Agricultural farming in Japan. During the post-World War II economic boom in Japan, agriculture faced a decline. New policies created a large dependency on imported foods. Owing to neoliberal trade strategies since the 1980s, small and mediumscale farmers have been forced to compete with large-scale farmers and the import of agricultural products has accelerated (Kinezuka and De Wit, 2020). This has added another factor to the list of reasons (which include ageing, relocation, fascination with city life: these factors have also been explored in detail in the present research) that have caused a significant decline in farming in Japan. Now Japan's food self-sufficiency rate at $38 \%$ is dismally low (Kinezuka and De Wit, 2020). Hokkaido is the biggest prefecture in Japan by area, with $1,145,000$ ha of arable land, which accounts for 26\% of Japan's total (Ministry of Agriculture, Forestry and Fisheries, 2018). The management area per farm household in Hokkaido is about 14 times as large as elsewhere in Japan, averaging $27.1 \mathrm{ha}$. The numbers in cooperative and corporation farming have been increasing recently (Hosoyama, 2011). However, in Hokkaido, where the rate of family farming is $98 \%$, farms become short of workers when the management area exceeds 20 ha (Nihei, 1991). The declining trend in the number of farmers has been observed throughout Japan. Similarly, in Hokkaido, the management area per farm household is tending to increase rapidly. If the current farmers decline rate stays unchecked and continues to grow at the same pace then it is predicted that core farmers in some areas will need to expand their manageable land area to 50 ha by 2030 (Hosoyama, 2013). This will have far-reaching effects on the country's basic food production self-sufficiency, as the necessary skill and manpower needed to grow basic food crops like rice is vanishing with the passage of time (Hosoyama, 2011). With the current outbreak of coronavirus (Covid-19), many countries are closing their borders and the food supply chain is under strain (Cullen, 2020). The concept of social distancing and quarantining is affecting the food processing and production capabilities of numerous food exporting countries. Though the current issue may look temporary, now it is time to think about the promotion of domestic agriculture so that Japan can reduce its international dependency on basic food supplies.

History of the education system in Japan. Before World War II, there was a double-track education system in Japan at the level above primary education. One track of education lead to junior high school, high school, and university. For those who had completed mandatory primary education, the other track was one which fed into vocational schools and vocational colleges that 
were virtually equivalent in scope to institutions of higher education (Amano, 1993).

After World War II, there was a transfer from the double to a single-track Japanese education system; i.e., junior high school, high school, and university. This system of education depends mostly on tuition fees rather than being publicly funded. Many of the former vocational schools and colleges became universities under the new system. In the meantime, there was a heavy demand from the industrial sector to re-introduce the pre-war short-term professional higher education. Consequently, "vocational colleges" or "vocational universities" were conceived, however in 1961, the system of "colleges of technology" was launched. The duration of the study in these schools is 5 years. Students could enter after the junior high-school graduation and the college of technology offered an equivalent of a 3-year highschool education and a 2-year higher education. However, due to financial constraints, these institutions do not serve as preparatory institutions for students desiring to transfer to 4-year universities. At present, only about 10,000 students enroll in these, which constitutes less than $1 \%$ of the coeval population (Kaneko, 2019).

In 1960, university enrollment for the 4-year course rose significantly and in the mid-1970s it was well above $30 \%$. In the current decade, it is around $50 \%$, creating the "massification of higher education" in Japan (Kaneko, 2019). This has largely been driven by two factors: (i) Accompanying rapid economic development, there was a growth in household incomes that provided many high-school students a chance to enter university who would previously have given up due to financial reasons. (ii) With the economic growth, there was a high demand for personnel for modern occupations, though these professions alone were insufficient to engage the growing number of graduates. However, in corporate management organizations, industrial growth resulted in an increase in white-collar workers. These jobs tended to go to university graduates.

With enrollment growing to nearly $20 \%$ of the age- 18 population, the professional training college system showed substantial growth. However, at the same time, the number of students desiring to enter university also increased continuously and the entrance examinations became highly competitive. This created a general social perception of the students choosing professional and vocational education doing so because either academic performance or financial constraints prevented them from entering 4-year universities (Kaneko, 2019).

In terms of the focus of the present research, the farming field, there are a number of agriculture-related high schools in Hokkaido (Knowledge Station), where the students can enroll with the idea of taking over the family farming business. However, firstly, the institutions' number is quite small considering the current situation and size of Hokkaido. For instance, if one were to compare number of institutions per land mass, the number of agricultural high schools in Hokkaido is less than half that of the island of Kyushu, despite Hokkaido being twice Kyushu's size. Such a small number of agriculture-related high schools can be indicative of either a low demand among the youth, weak support from the government, or both. Secondly, throughout our survey, we have never come across a single farming family whose children had enrolled in agriculture-related high schools. Furthermore, research by the Norinchukin Research Institute indicates that only $2.5 \%$ of graduates of even agricultural high schools go directly into farming careers, and that rather they tend to only take up work after having finished college, junior college or agricultural college (Ueno, 2013). These trends may indicate that career research focusing on motivational factors to attend post-secondary agricultural colleges or vocational institutes is necessary. At the same time, to understand the imbalance of unemployment in the city areas and vacant slots in the rural areas, it is important to focus on the career selection tendencies of youth studying in the urban areas. For this purpose, we have selected Kaisei High School located in downtown Sapporo city for our current research.

Career guidance in Japan. In a review of career guidance in Japan, Tatsuno (2002) notes that there is a tendency to draw "the line between the academic course and the vocational course." In other words, career counseling in Japan has been heavily influenced by the two-track system described above, to the extent that at the university level, career guidance is focused almost solely on students attaining gainful employment in a corporation. Of course, this distinction also plays out at the high-school level between college-bound and non-college-bound high-school students (cf. Horvath, 1986), with different systems of career counseling for each. For the purposes of this paper, it is important to clarify that, contrary to for example the US and Canada, countries often cited for their well-developed counseling systems wherein career counseling is a specific job category conducted by trained specialists with expertize in the discipline, Japanese high schools possess no system of professional career counselors. Rather, within its schooling system Japan adopts a "Department store-type" approach to student support, wherein individual teachers are responsible for academic, vocational and life counseling, which is conducted as part of everyday classroom management (Tatsuno, 2002). Similarly, in Japan, there exists no clear definition of "career education", and, while Japan has occupational classifications, there are no information resources to match the individual with a relevant occupational trait or address supply and demand issues within the labor market, such as the Occupational Outlook Handbook published by the US Department of Labor (cf. Tatsuno 2002). We suggest that more precise career counseling based on in-depth descriptions of occupational traits and supply and demand statistics within relevant fields should be provided.

Given that there are a limited number of agricultural high schools in Japan, research into pre-vocational institute career guidance is also in order, but is beyond the scope of this paper.

\section{Objectives}

This study firstly explores the connection between aging and the shortage of agricultural workers. As our second objective, we want to observe the career selection tendencies of the youth and understand their opinion about farming. This will enable us to draw some conclusions about the agricultural field and suggest a few recommendations for influencing youth career selection.

\section{Materials and methods}

This research was conducted over the course of 4 years, from 2013 to 2017. To address the first objective, we contacted farm corporations and conducted a series of interviews with a total of twenty farmers who mainly grow rice and different vegetables in Hokkaido. All the interviewed individuals were full-time farmers. Some of the interviews were conducted through the cooperation of the Japan Agricultural Cooperatives (JA). For the others, the first author volunteered himself for various farming activities and supported farmers during cultivation and harvest seasons and the interviews were conducted at those times. Also, information was gathered by participating in various farming festivals and events in various parts of Hokkaido. Interview content focused on issues related to agricultural demographics, including children's career paths after having gone to urban areas for higher education. To supplement this data, surveys at farming corporations were also conducted. 
To explore answers for the second objective, it is important to understand young people's career selection tendencies. Adolescents must make critical decisions; after graduation from high school, they either enter the labor force or continue their education. If they choose the latter, they must select a post-secondary institution (Featherman, 1980). A study conducted at Yamaguchi University by Usman and Tomimoto (2013), predicted that an over- or under-supply of workers in some fields can become a serious problem for Japan. A field will become saturated when too many people enter it. There might be intense competition for jobs in one field while another has job vacancies waiting to be filled. For the current research, Kaisei High School located in Sapporo City of Hokkaido Prefecture was selected for the study. The 157 students who participated in this research were $16-18$ years of age. They were asked questions regarding their choice of future career field, motivation for this choice, and, for the purposes of this paper's topic, their impressions of farming as a lifestyle/career choice. Data on the target population was not disaggregated according to gender or other attributes.

Based on the data, we have divided the students' selected fields into two categories: Science and Technology, and Others. All the students who have selected a field commented on their choice in the "Reason" section of the questionnaire. The reason for future field selection reveals which percentage of students is entering a field that was recommended by parents, teachers or friends, and vice-versa how many students report having had no significant influence from them.

\section{Results}

The interviews with farmers, JA representatives and farming corporations in Hokkaido showed that the farmers living close to Hokkaido urban areas prefer to grow vegetables rather than grain crops. On the other hand, farmers living in remote areas prefer to grow various grain crops. Compared to the latter, the fresh vegetables have relatively high payout; however, their quality deteriorates quickly. Also, preparing the fresh vegetables is relatively more labor intensive as the harvest season can last from several weeks to a few months. Owing to the proximity of the main market, farmers can sell the products on a daily basis (which seems quite hard for the farmers living in the remote rural areas). As old age starts to take over, the farmers living in the vicinity of the city areas come to prefer to cultivate grain crops. Now, with the limited number of descendants supporting family farming and the farming corporations having a hard time finding young employees, one can foresee a possible decline in vegetable farming relative to grain farming in the near future.

Interview results indicated that most farmers have families and children, and very few are single. All those who are married, wanted children. Children stay with these families mainly through elementary school. After that, they go to big cities like Sapporo for junior high school, high school, college or university. However, once they have finished their studies, they rarely return to the family farm.

The high-school questionnaire results indicate that around half of the students $(50.3 \%)$ have already decided on a future career. Among them, $76 \%$ want to have a job in science and technology. Details of the fields selected by the students are given in Figs. 1 and 2 and their reasons for choosing that field are given in Fig. 3.

The data from our high-school questionnaires as well as interactions with the students indicates four factors that cause youth to move away from farming: (i) a fascination with science and technology-related careers and (ii) city life, (iii) an exaggerated image of losses associated with a sudden change in the weather patterns, and (iv) the financial constraints related to starting one's own farming business. This situation of students

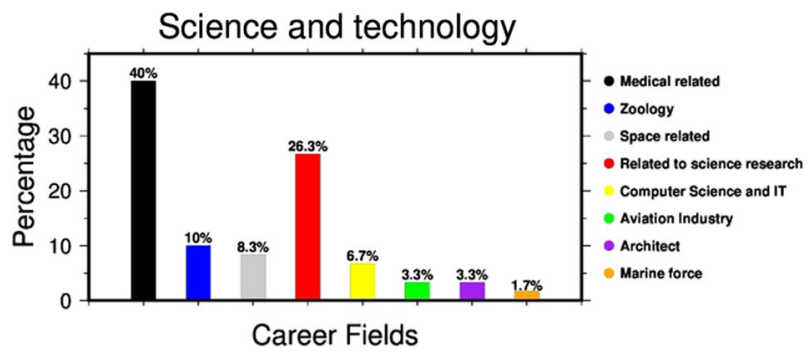

Fig. 1 Desired future career - science and technology. Breakdown of science and technology fields selected by the students (according to percentage).

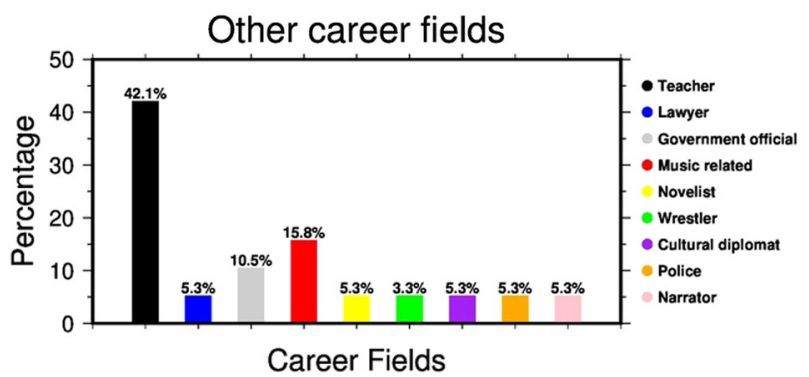

Fig. 2 Desired future career - other fields. Breakdown of other fields selected by the students (according to percentage).

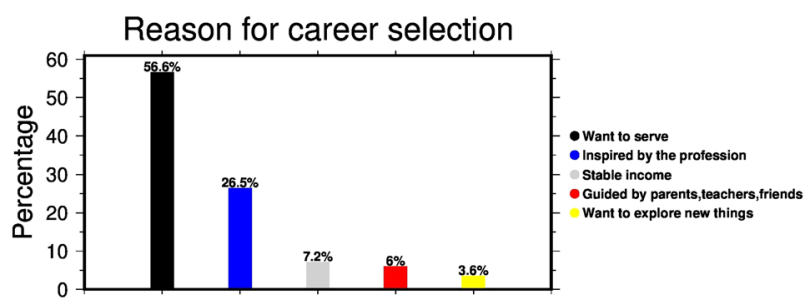

Fig. 3 Reason for career selection. Reason for the future career selection.

leaving the rural areas for the cities, and then choosing careers paths, which will allow them to remain there, bodes darkly for rural agricultural community sustainability.

\section{Discussion}

Socio-economic implications of current relocation trends. Worldwide, though the issue of ageing is becoming challenging for many countries, there are significant differences in the demographic trends in rural and urban areas. The phenomenon of ageing is more dominant in the rural areas than the cities (OECD, 2016). Japan is no exception. In comparison to other prefectures in Japan, Tokyo has a $4.6 \%$ lower proportion of people aged 65 or above. One needs to understand that the current fertility rate of Tokyo in Japan is among the lowest in the world; i.e., 1.15 births per woman in 2014 (Cabinet Office of Japan, 2016). So, the main factor contributing to the situation of Tokyo retaining the lowest percentage of the elderly (Kudo, 2020) is related to the migration of youth from other prefectures. During the rapid economic growth period of Japan (i.e., from 1954 to 1974) around 7.15 million people migrated to Japan's three major metropolitan areas of Tokyo, Osaka, and Nagoya. Even today, a similar migration pattern is observed to the Tokyo metropolitan area, which is resulting in economic decline in the rural regions (Nihon Sousei Kaigi, 2014). We also have observed similar kinds of trends in the rural areas of Hokkaido. Our interviews with farmers and JA representatives indicate that 
though the majority of farmers have children, these youngsters leave for higher education to the main city areas and after completion of necessary education prefer to do an office job in the cities rather than returning back to their native village (Figs. 1 and 2 ). The general retirement age throughout Japan is 65. In Hokkaido, where the rate of family farming is $98 \%$ (Nihei, 1991), the lack of support from the young generation in the farming field forces the older-aged farmers to continue working well past retirement age. Though a single farming couple (husband and wife), with all the necessary machinery, can take care of around 10 ha of land (if they grow rice, wheat and other grain crops), as the couple grow older and with the deterioration of physical strength, they prefer to cultivate the land close to their home and the manageable area becomes smaller and smaller with the passage of time.

Our field surveys indicate that the rural regions are now facing different challenges related to everyday life: less accessibility to medical care, infrequent public transportation and loneliness. At the same time, this has serious implications on the regional scale, resulting in regional economic and community vitality decline. If viewed in terms of the concept of sustainability, which is commonly understood as being related to the expansion of human activities, the demographic trend in Japanese society of an aging and population drop, expected to proceed further in decades to come, makes it unclear what to sustain (Kudo, 2020). While there has been a transition from past social structures to new social configuration, this situation requires new social designs in which one can include all the different variables for the planning of policy related to sustainable development.

Current career selection tendencies in Japan and their impacts on unemployment and farming. The second demographic transition theory explains the tendency to live in cities where population trends from familism to individualism (Van de, 1987). Yet, sustainable urban development is a balance of economic growth, environmental issues and social conditions (Zinatizadeh et al., 2017) and has many challenges of its own (Jansen, 2003). In Japan, the capacity to live alone in an urban area is restricted by a person's economic condition, which is related to limited availability of jobs in government sectors, and the strict rules and limited salary of private-sector jobs (Usman and Tomimoto, 2013). There are more jobs available nationwide; however, Japan's unemployment rate has remained flat (JT, 2016) with a slight increase in recent times (JT, 2018). Though the Japan Times $(2016,2018)$ has not distinguished between the unemployment rate in urban and rural areas, our research indicates that, with the passage of time, more and more workers will be needed in the rural areas. The flat unemployment rate on the one hand and vacant slots on the other gives indication of an unbalanced societal approach toward career selection and can be considered to be related to the aging of the population and current relocation trends discussed above.

Overall career selection trends and the prospective role of specialized career counseling. During adolescence, young people make critical decisions (Featherman, 1980; Duryea et al., 2003; Jaroslawska et al., 2020). Our survey results at Sapporo Kaisei Secondary School show that the adolescents who have already decided about their career paths are strongly influenced by jobs in science and technology (around 76\% want to join this field). This aligns with previous research at Yamaguchi University, in which nearly $2 / 3$ of youth planned to enter the engineering and applied sciences field and only $1 / 3$ were interested in the natural and social sciences and economics (Usman and Tomimoto, 2013). Meanwhile, our research at Kaisei High School indicates that nearly $50 \%$ of the students have not decided about their career path, and these figures further appear to follow the general trend career path selection at Hokkaido University (as indicated by interviews conducted by the authors with the Hokkaido University Office of International Affairs). In these universities, the proportion of the youth studying in various fields suggests that the nearly $50 \%$ of high-school adolescents who have not yet decided about their future field, is probably influenced by the general tendency of career selection by other students.

Adolescents' career aspirations have also been shown to be influenced by family environment, and parents provided most of the career-related information for adolescents (Saltiel, 1985; Majoribanks, 1986; Sebald, 1989; Duryea et al., 2003; Suryadi et al., 2020). However, our research reveals that $<6 \%$ of the students who have already decided on a field report having been influenced by parents, teachers or friends (Fig. 3). Most of the students seemed to have been motivated either by the profession, or by professionals (Fig. 3). It is also important to note that our studies found the high school provides only general guidance for the career of adolescents. We suggest given this current lack of guidance from other sources that the school should provide more in-depth guidance to the students about jobs available to them.

Meanwhile, it is indicated by Jung (2017) that a probable predictor of highly able adolescent's attitudes toward careers are whether a future career will be interesting or enjoyable for them or not. Sapporo Kaisei Secondary School is a prestigious high school, well-known for preparing students to enter university. Previous study suggests that students who have abilities higher than the average fellow get prepared and try to plan early for the future (Jung, 2017). Amidst such a situation, social policies may need to be modified to facilitate young people's quest for vocational identity and work (Mortimer et al., 2002). As the schools do not have a specialty career counseling service for the high-school students, we suggest that the schools should introduce such services and provide counseling based on indepth job descriptions as well as detailed updates about the real job availability and competition situation in each field based on current supply and demand figures. This might help these bright young people to select a field by considering all of its advantages and disadvantages.

As indicated by the present research and also by Usman and Tomimoto (2013), the intense competition related to the science and technology jobs can be a possible factor maintaining Japan's flat unemployment rate. To rectify this situation, it is important to appeal to the indigenous workforce effectively, as unforeseen developments can also play an important role in the career decision-making of students (Bright et al., 2004). Here again, the lack of any specialized career counseling at school indicated by our investigations comes into bearing.

Specific suggestions for shifting interest to under-represented farming-related professions. As above, the main reasons why young people in Japan do not want to adopt farming as their career path revolve around four factors: the first is a fascination with jobs related to science and technology. Secondly, they wish to remain in the city. Thirdly, the risks involved related to farming, especially typhoons and climate change impacts are overestimated and exaggerated in their minds. Lastly, as farming is considered a private business, the initial capital needed to start farming seems to be another hurdle.

Based on the survey results and discussion, our suggestion regarding the above-mentioned first two factors, is a further pilot study, the grounds being the provision to the students of real statistical information (by including the data of workplace saturation and job availability in various fields) about the level of competition in various fields in the urban areas and career 
opportunities available in rural ones (like farming in this case). A general Japanese social perception about choosing professional and vocational education and even farming, in this case, is related to academic performance. Though it is likely that the students with superior academic performance will wish to take the challenge of competition, as indicated by Kaneko (2019), provision of unbiased statistical information might open the eyes of those bright students who cannot compete for careers related to science and technology to the option of farming as a field. As a result, they could still follow a career path somewhat related to science and technology and choose those agriculture-related jobs that would leave them a chance to stay close to the cities. At the same time, as our research indicated that nearly $50 \%$ of the students have not decided about a career path, there is a chance that this "undecided" population of students can be influenced once they are provided with concrete information through school sources. Finally, web information and social media can play a role in students' career decision-making (Bright et al., 2005) so to promote farming-related careers it is also suggested to use media outlets as well.

As for the third and the fourth factors, these are mainly related to having incorrect information. Misinformation is also regarded as a major factor that compels students to move away from one occupation and select another (Gati et al., 2013), though it is a matter for further investigation how many students move away from farming due to heavy expected losses. Japanese youth have a perception that storms and climate change impacts can destroy fields so much that one cannot survive until the next season. However, this is not the case with most farmers in Hokkaido. It is true that typhoons and sudden changes in weather patterns bring damage to the crops, but the losses during a typical year are not so severe that the average farmer cannot survive till the next crop season. This point can be explained by providing students detailed and accurate information about farming during the prevocational institute period of their education. As far as the fourth factor is concerned, there are start-up programs run by the government for those who wish to start farming as a career. This kind of information can be shared with the students and can be helpful to raise their interest in the farming field.

It is further suggested that there should be an increase in the number of vocational training institutes that can provide students a chance to learn through experience of real farming activity. Success of farming-related vocational institutes all depends upon the demand among the students and our data indicates that there is nearly no demand among the young people for farming due to the above-mentioned four major factors. So, it is important that the students be provided farming-related necessary information during the pre-vocational institute time. This can raise students' interest in the farming field and possibly the number of students entering the farming-related proposed vocational institutes would increase. Data (Ueno, 2013) indicating that the majority of children from farming families who attend agricultural high schools also go on to junior college, college or agricultural college before entering the farming profession indicates that high school is not a threshold beyond which one can begin the study of agriculture neither in terms of age nor motivation, and in that sense increasing the number of agricultural vocational institutes is a viable option.

In this research, due to the privacy policy of Sapporo Kaisei Secondary School, we have focused on the cumulative trend of the youth rather than disaggregating the data on the basis of gender, class or disability. Though the present data from Sapporo Kaisei Secondary School indicate that the youth have virtually no interest in farming, these results are only indicative, and not conclusive. It is suggested to include data from other high schools across Hokkaido in future studies to test the current research results.

\section{Conclusions}

In the rural areas of Hokkaido, the relocation of youth to the cities is probably the main cause of the aging of the population and the shortage of workers. In the city areas, youth tend to select careers in science and technology, which probably creates high competition in those fields. At the same time, it leaves vacancies in fields related to agricultural farming. In high schools, the teachers provide only general guidance for career selection, rather than in-depth descriptions of occupational traits or explanations regarding the amounts of competition in some fields. It is suggested that proper counseling should be done so that adolescents make more informed career choices.

On the basis of this study, we also suggest increasing the number of farming-related vocational institutes in Hokkaido. While this study has also indicated that the students have virtually no interest in agricultural farming, the demand for farming institutes can possibly be created by introducing appropriate farming-related educational units in earlier stages of education as well as through other, non-schooling measures such as the dissemination of correct information through media outlets.

\section{Data availability}

The datasets generated during the current study are not publicly available due to confidentiality of the respondents' information. However, further information is available from the corresponding author pending upon reasonable request.

Received: 18 July 2019; Accepted: 25 November 2020; Published online: 20 January 2021

\section{References}

Amano I (1993) Kyusei senmon gakko ron [The prewar vocational school system in Japan]. Tamagawa University Press, Tokyo

Bermingham JR (2001) Immigration: not a solution to problems of population decline and aging, population and environment. J Inter Stud 22(4):355-363

Bright JEH, Robert GL, Lucy H (2004) The role of chance events in career decision making. J Voc Behav 66:561-576

Bright JEH, Robert GL, Welkenfeld S, Earl J (2005) The role of social context and serendipitous events in career decision making. Inter J Edu Voc Guid 5:19-36. https://doi.org/10.1007/s10775-005-2123-6

Bubic A, Ivaniševi CK (2016) The role of emotional stability and competence in young adolescents' career. J Career Dev 43:498-511. https://doi.org/10.1177/ 0894845316633779

Cabinet Office of Japan (2016) Kourei Shakai Hakusho (White paper report on the aging society 2016 高齢社会白書2016). Tokyo. Available via DIALOG. http://www8.cao.go.jp/kourei/whitepaper/w-2016/zenbun/28pdf_index.html

COEC (2007) Europe's demographic future: facts and figures. Commission of the European Communities. Available via DIALOG. http://ec.europa.eu/ employment_social/social_situation/docs/sec_2007_638_en.pdf

Cohen B (2006) Urbanization in developing countries: current trends, future projections, and key challenges for sustainability. Tech Soc 28:63-80. https:// doi.org/10.1016/j.techsoc.2005.10.005

Coleman D (2006) Population ageing: an unavoidable future. The welfare state. Available via DIALOG. https://books.google.com.sa/books?hl=en\&lr=\&id= $\mathrm{kSwy} 6 \mathrm{f0PghMC} \& \mathrm{oi}=$ fnd\&pg $=\mathrm{PA} 298 \& \mathrm{dq}=$ unsustainable + immigration + solution + to + ageing\&ots $=\mathrm{bEHFZ49cfG \& sig}=$ mxLUzfltWkprETIVe FYx8agmf4\&redir_esc $=\mathrm{y} \# \mathrm{v}=$ onepage $\& \mathrm{q}=$ unsustainable $\% 20$ immigration $\%$ 20solution\%20to\%20ageing\&f=false

Cullen MT (2020) Food supply chain under strain what to do? Food and Agricultural Organization of United Nations. Available via DIALOG. http://www. fao.org/3/ca8308en/ca8308en.pdf

DAHG (2017) Agriculture in Hokkaido Japan. Department of Agriculture Hokkaido Government (DAHG). Report. Available via DIALOG. http://www. pref.hokkaido.lg.jp/ns/nsi/genjyoutokadai_english_2901.pdf

Duryea S, Edwards AC, Ureta M (2003) Adolescents and human capital formation. In: Duryea S, Edwards AC, Ureta M (ed) Critical decisions at critical age: adolescents and young adults in Latin America. Interamerican Development Bank, Washington, DC

Eberstadt N (2010) The demographic future what population growth-and decline -means for the global economy. Foreign Aff 89(6):54-64 
Featherman DL (1980) Schooling and occupational careers: Constancy and change in worldly success. In: Brim OG, Kagan J (ed) Constancy and change in human development. Harvard University Press, Cambridge, MA, p 675-738

Francks P, Boestel J, Kim CH (1999) Agriculture and economic development in East Asia: from growth to protectionism in Japan, Korea, and Taiwan. Routledge, London UK

Gati I, Ryzhik T, Vertsberger D (2013) Preparing young veterans for civilian life: the effects of a workshop on career decision-making difficulties and selfefficacy. J Voc Behav 83:373-385. https://doi.org/10.1016/j.jvb.2013.06.001

Horvath P (1986) Career counseling for non-college bound high school seniors in Japan. Office of Educational Research and Improvement (ED). Washington DC. Report. Available via DIALOG. https://files.eric.ed.gov/fulltext/ED271404.pdf

Hosoyama T (2011) Development and characteristic of Hokkaido rural societytrend of farmer and land and village, after the latter half of the 1980's. Res Bull Natl Agric Res Cent for Hokkaido Region 193:11-39

Hosoyama T (2013) The future scale and its regionality of a large-scale farmhouse in the Hokkaido paddy field zone. Hokunou 80(4):416-420. (in Japanese)

IPSS (2014) National Institute of Population and Social Security Available via DIALOG. http://www.ipss.go.jp/s-info/e/ssj2014/003.html

Kaneko M (2019) Universities: the formulation of professional and vocational universities: background and challenges of a new institutional type in Japan. Jap Lab Iss 13(3):30-42

Kaneko R, Ishikawa A, Ishii F, Sasai T, Iwasawa M, Mita F, Moriizumi R (2008) Population projections for Japan: 2006-2055 outline of results, methods, and assumptions. Jap J Pop 1(6):76-114

Kinezuka A, De Wit MM (2020) Food sovereignty in Japan and beyond. In: Jayaraman S, Master KDE (eds) People taking on corporate food and winning. Univ of California Press, pp. 192-202

Koshiyama N (2019) Influence of field water management by land consolidation in paddy field zone in Hokkaido Japan. Irrig Drain 68:103-108. https://doi.org/ $10.1002 /$ ird. 2323

Knowledge Station (n.d.) List of high schools in Hokkaido specializing in agriculture. Available via DIALOG. https://www.gakkou.net/kou/src/? srcmode $=$ bn\&bn $=1001 \& p=1$ (in Japanese)

Kudo S (2020) Framing in placemaking when envisioning a sustainable rural community in the time of aging and shrinking societies in Japan. In: Mino T, Kudo S (ed.) Framing in sustainability science: theoretical and practical approaches. pp. 97-118. Springer

Jansen L (2003) The challenge of sustainable development. J Clean Prod 11:231-245 Japan Cabinet Office (2018) Annual report on the aging society. Available via DIALOG. https://www8.cao.go.jp/kourei/english/annualreport/index-wh.html

Jaroslawska AJ, McCormack T, Burns P, Caruso EM (2020) Outcomes versus intentions in fairness-related decision making: school-aged children's decisions are just like those of adults. J Exp Chi Psy 1-25. https://doi.org/10.1016/ j.jecp.2019.104704

JT (2016) Japan's job availability hits record high but unemployment rate remains flat. Available via DIALOG. http://www.japantimes.co.jp/news/2016/05/31/business/ japans-job-availability-hits-record-high-but-unemployment-rate-remains-flat/

JT (2018) Unemployment rate ticked up in November, but labor market remains tight: ministry. Available via DIALOG. https://www.japantimes.co.jp/news/ 2018/12/28/business/economy-business/unemployment-rate-tickednovember-labor-market-remains-tight-ministry/

Jung YJ (2017) Occupational/career decision-making thought processes of adolescents of high intellectual ability. J Edu Gif 1(40):50-78

MAFFJ (2017) FY2015 annual report on food, agriculture and rural areas in Japan. Ministry of Agriculture, Forestry and Fisheries Japan (MAFFJ). Available via DIALOG. http://www.maff.go.jp/e/data/publish/attach/pdf/index-35.pdf

Majoribanks K (1986) A longitudinal study of adolescents aspirations as assessed by Seginer's model. Mer Pal Quar 3(32):211-230

Ministry of Agriculture, Forestry and Fisheries (2018) Agriculture and Forestry Fisheries Statistics. Available via DIALOG. http://www.maff.go.jp/j/tokei/ [Accessed on 30 October 2018] (in Japanese).

Mortimer JT, Zimmer-Gembeck MJ, Hplmes M (2002) The process of occupational decision making: patterns during the transition to adulthood. J Voc Behav 3(61):439-465. https://doi.org/10.1006/jvbe.2002.1885

Nihei T (1991) The structure of works in rice production and the scale limit in Hokkaido. Res Mater Hokkaido Agric Exp Stat 43:1-18 (in Japanese)

Nihon sousei kaigi [Japan Policy Council] (2014) Stoppu shoushika chihou genki senryaku（ストップ少子化・地方元気戦略 Stop depopulation strategies for regional vitality). Available via DIALOG. http://www.policycouncil.jp/

Nishi and Kan (2006) Current situation of Parasite-singles in Japan (Summary), Statistical Research and Training Institute, Japan. Available via DIALOG. https://www.stat.go.jp/training/english/reseach/parasite_eng.pdf

OECD (2016) Population and migration estimates. OECD Factbook. OECD. https://doi.org/10.1093/oxfordhb/9780199589531.013.0035

Robertson PJ (2014) Health inequality and careers. Br J Guid Coun 3(42):338-351. https://doi.org/10.1080/03069885.2014.900660
Saltiel J (1985) A note on models and definers as sources of influence in the status attainment process: Male-female differences. Soc For 4(63):1069-1075. https://doi.org/10.1093/sf/63.4.1069

Sebald H (1989) Adolescents' peer orientation: changes in the support system during the past three decades. Adolescence 24(96):937-946

Shin MW, Kim BHS (2019) The effect of direct payment on the prevention of farmland abandonment: The case of the Hokkaido Prefecture in Japan. Sustainability 12(334):1-13. https://doi.org/10.3390/su12010334

Suryadi B, Sawitri DR, Hayat B, Putra MDK (2020) The influence of adolescentparent career congruence and counselor roles in vocational guidance on the career orientation of students. Inter J Inst 13(2):45-60. https://doi.org/ 10.29333/iji.2020.1324a

Suzuki T (2006) Fertility decline and policy development in Japan. Jap J Pop 4(1):1-32

Tatsuno R (2002) Career counseling in Japan: today and in the future. Car Dev Quar 50(3):211-217

United Nations (2001) Replacement migration: is it a solution to declining and ageing populations? Available via DIALOG. https://books.google.com.sa/ books?hl=en\&lr $=\& \mathrm{id}=$ AukLnuo9jCkC\&oi $=$ fnd \&pg $=$ PR3\&dq $=$ united + nations + population + division $+2001 \&$ ots $=t f 1$ t8N9cuC\&sig $=8 \mathrm{qx}$ UEfYtzHmAmvxWPs0SGwuykpQ\&redir_esc $=\mathrm{y} \# \mathrm{v}=$ onepage\&q $=$ united $\%$ 20nations\%20population\%20division\%202001\&f=false

Ueno T (2013) Farming education in Japan. Available via DIALOG. https://www. nochuri.co.jp/report/pdf/n1404re2.pdf (in Japanese)

Usman M, Tomimoto I (2013) The aging population of Japan: causes, expected challenges and few possible recommendations. Res J Rec Sci 2(11):1-4

Van de KD (1987) Europe's second demographic transition. Pop Bull 42(1):1-59

Villanueva $\mathrm{AB}$ (2000) Review essay: population aging and retirement issues in the next millennium. Soc Sci J 37(2):321-325. https://doi.org/10.1016/S03623319(00)00070-7

Yamanaka K (1993) New immigration policy and unskilled foreign workers in Japan. Pac Aff 66(1):72-90

Yashiro N (1997) Aging of the population in Japan and its implications to the other Asian countries. J Asi Econ 8(2):245-261. https://doi.org/10.1016/S1049-0078 (97) $90019-1$

Yokoyama K, Birchley SL (2020) Transnational entrepreneurship in South East Asia. Springer.

Zinatizadeh S, Azmi A, Monavari SM, Sobhanardakani S (2017) Evaluation and prediction of sustainability of urban areas: a case study for Kermanshah city, Iran. Cities 66:1-9. https://doi.org/10.1016/j.cities.2017.03.002

\section{Acknowledgements}

We are thankful to the two anonymous reviewers as their comments helped to improve the manuscript. We are also indebted to Mr. Kenichi Horiguchi and his team from Japan Agricultural Cooperatives (JA) Sapporo office for their support. Also, we are thankful to Prof. Dr. Susumu Ohnuma, Department of Behavioral Science, Hokkaido University, for his support.

\section{Competing interests}

The authors declare no competing interests.

\section{Additional information}

Correspondence and requests for materials should be addressed to M.U.

Reprints and permission information is available at http://www.nature.com/reprints

Publisher's note Springer Nature remains neutral with regard to jurisdictional claims in published maps and institutional affiliations.

Open Access This article is licensed under a Creative Commons Attribution 4.0 International License, which permits use, sharing, adaptation, distribution and reproduction in any medium or format, as long as you give appropriate credit to the original author(s) and the source, provide a link to the Creative Commons license, and indicate if changes were made. The images or other third party material in this article are included in the article's Creative Commons license, unless indicated otherwise in a credit line to the material. If material is not included in the article's Creative Commons license and your intended use is not permitted by statutory regulation or exceeds the permitted use, you will need to obtain permission directly from the copyright holder. To view a copy of this license, visit http://creativecommons.org/ licenses/by/4.0/

(c) The Author(s) 2021 